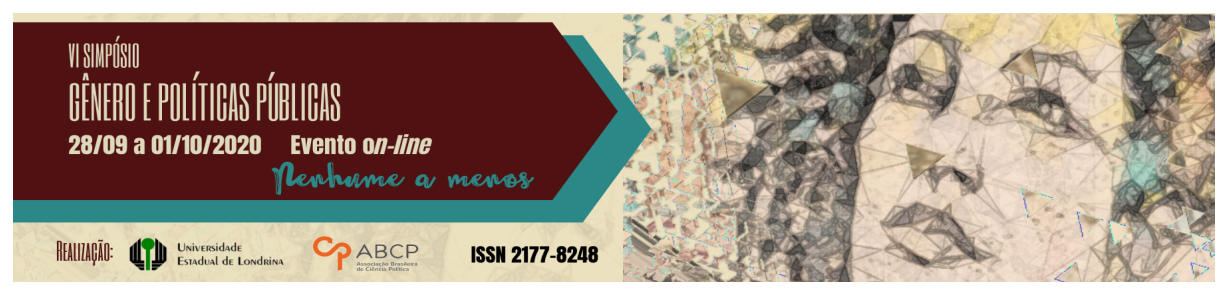

\title{
O conceito de laicidade em Católicas pelo Direito de Decidir
}

\author{
Sophia Teixeira e Souza ${ }^{1}$
}

\section{Resumo}

Este projeto de artigo objetiva identificar qual o papel do movimento Católicas pelo Direito de Decidir na disputa entre religião e secularismo na temática dos direitos das mulheres ao próprio corpo. Mobiliza-se o conceito de laicidade e o material disponibilizado online pelas próprias Católicas pelo Direito de Decidir. Analisamos como o grupo se utiliza da retórica da laicidade em suas arguições a favor da descriminalização do aborto. A partir do pressuposto de que o catolicismo ainda é uma religião pública, debateremos a complexa e controversa localização da mulher e da religião nos espaços público e privado e se a autoidentificação do grupo com o catolicismo é indício de dessecularização ou forma de legitimar a sua principal pauta. Os resultados preliminares mostraram que as Católicas disputam com a Igreja Católica a atualização da agenda pública brasileira, abrindo em si mesmas a possibilidade de empenho como um movimento de base para reformas.

Palavras-chave: feminismo; catolicismo; aborto.

\section{The concept of laicity in Catholics for Choice}

\begin{abstract}
This draft aims to identify what is the movement Catholics for Choice's role in the dispute between religion and secularism in the theme of women's rights to their own bodies. The concept of secularism and the material made available online by Catholics for the Right to Decide are mobilized. We analyze how the group uses the rhetoric of secularism in its arguments in favor of decriminalizing abortion. Based on the assumption that Catholicism is still a public religion, we will discuss the complex and controversial
\end{abstract}

1 Universidade Federal do ABC (UFABC), bacharela e mestranda em Relações Internacionais, sophiatesouza@gmail.com.

GT 10 - Gênero e religiosidades 
location of women and religion in public and private spheres and whether the group's self-identification with Catholicism is an indication of desecularization or a way to legitimize its schedule. Preliminary results showed that Catholics are competing with the Catholic Church to update the public agenda, opening up in themselves the possibility of engagement as a grassroots movement for reforms.

Keywords: feminism; catholicism; abortion.

\section{Introdução}

No ambiente universitário, sobretudo nas faculdades e institutos de Ciências Humanas e Sociais, é senso comum a suposição de que religiões, enquanto sistemas hierarquicamente organizados de dogmas e moralidades, são fonte de conservadorismo, ignorância e preconceito. Portanto, estudantes esclarecidos e progressistas não seriam fiéis de qualquer igreja, dada a necessidade de incorporar e promover objetivos culturais frequentemente identificados com o espectro político de esquerda. Pautas como direitos de identidade de gênero, direitos sexuais e reprodutivos não são, segundo esta lógica, defendidas por cristãos.

Por mais facilitadora que possa parecer essa generalização, não é verdadeira. Aqui trabalharemos com a organização Católicas pelo Direito de Decidir, grupo presente em diversos países latinoamericanos, cujo foco de atividade são os direitos reprodutivos de mulheres, sobretudo pela defesa da legalização do aborto. As Católicas é uma representação em si mesma da disputa entre o religioso e o secular no cenário político brasileiro em temas de controle dos corpos femininos pelo Estado.

Para discutir como esta relação é possível, inicialmente apresentaremos o conceito de laicidade segundo algumas perspectivas que interseccionam o diálogo entre religião e Estado contemporâneos. Em seguida, apresentaremos as Católicas, seu histórico, formas de atuação e posicionamentos ideológicos. Dessa forma, discutiremos como o grupo se utiliza da retórica da laicidade em suas arguições 
para responder qual o seu papel na disputa entre religião e secularismo na temática dos direitos das mulheres ao próprio corpo. Trabalhamos com a hipótese a priori de que o papel das Católicas é, distante do pressuposto da conciliação entre dois campos inicialmente opostos - feminismo e religião -, mas de disputa do espaço das políticas públicas com setores tradicionais da Igreja.

\section{Laicidade como conceito e como prática pelos direitos reprodutivos}

Das chamadas Jornadas de Junho às consequências da eleição de Jair Bolsonaro para a Presidência da República, um debate tem permeado as discussões sobre a política brasileira. Perguntamo-nos constantamente se estamos vivendo, nesta conjuntura, um "desencantamento" do mundo moderno, no qual a religião não mais teria capacidade aglutinadora, formadora de interesses e ações. Questionamos se há autonomia entre a esfera pública e valores religiosos ou se estes são empurrados para o âmbito privado, como preveriam os cânones da modernidade.

Apesar do catolicismo não ter a maior representatividade política no Brasil, seus efeitos constituintes da sociedade brasileira (enquanto cultura ocidental), permanecem. Católicas pelo Direito de Decidir tem, no contexto de redução do poder de influência política pela Igreja Católica nas instituições estatais, buscado uma teologia alternativa e atuado em consonância com movimentos sociais à esquerda: autoidentificando-se como "feminista" e favorável aos direitos LGBTQI, contrariando o senso comum sobre os dogmas de sua fé confessa. As ativistas buscam conciliar sua religião e seu favorecimento ao Estado laico ${ }^{2}$ nos assuntos públicos.

Para o fim analítico proposto, a partir daqui faz-se necessário explorar o sentido atribuído à laicidade por Católicas, uma vez que,

\footnotetext{
2 "Estado laico" é o termo utilizado nos documentos, notas públicas e artigos produzidos por Católicas pelo Direito de Decidir. Em nossa discussão, no entanto, nos ateremos ao termo "laicidade", de maior praticidade conceitual.
} 
tanto ideologias secularistas quanto religiosas mobilizam seus valores de uma ou outra maneira, a depender dos argumentos em disputa (MARIANO, 2011). De acordo com Mariano, a laicidade dispõe de maior precisão e operacionalidade em relação à neutralidade das instituições e do Estado em contextos plurais: a tolerância entre distintos credos, às liberdades de consciência e de culto (inclusive de não crer ou praticar). Além disso, refere-se à emancipação do Estado e do ensino público da necessidade de aprovação religiosa.

Diante do público, cidadãos crentes e não crentes, autoridades religiosas, políticos seculares e políticos representativos de seu culto, todos reconhecerão e defenderão o Estado laico. Em confrontos, contudo

[grupos laicos] tendem a defender, nos diferentes fóruns em que atuam, versões mais ou menos próximas do modelo (dito combativo) proposto pela tradição republicana francesa - que inspirou diversos processos de laicização na América Latina - , que zela pelo caráter laico do ensino público, pela rigorosa separação entre Estado e igrejas e pela restrição à participação e à influência de autoridades e grupos religiosos na esfera pública. Já os [religiosos] últimos tendem a reinterpretá-lo de modo lato, visando legitimar a ocupação religiosa do espaço público e da esfera pública, mas mantendo estrategicamente a referência discursiva, o respeito e certa reverência ao arranjo jurídicopolítico da laicidade estatal, até como recurso discursivo e legalista para garantir a legitimidade de sua própria intervenção no debate político (p. 253).

Essa apropriação por cada ramo de interesse nos parece indissolúvel segundo a tese da Dessecularização do Mundo de Peter Berger: de que não há causalidade necessária entre a secularização e a modernização, em que é possível uma sociedade construir um Estado moderno sem se desapegar de valores, condutas e símbolos religiosos; de que não há declínio da reprodução de práticas e crenças religiosos na modernidade (BERGER, 2000). A autoidentificação do grupo como 
católico é indício da dessecularização ou forma de legitimar a luta pela legalização do aborto?

Católicas pelo Direito de Decidir foi criado no Dia Internacional das Mulheres em 1993 no Brasil, como parte de um movimento feminista transnacional, que se organiza através de ONGs e indivíduos simpatizantes, dentre os quais mulheres intelectuais. À época, mulheres integrantes das Comunidades Eclesiais de Base passaram a querer lutar pela sua autonomia reprodutiva e, segundo consta em seu histórico o discurso condenatório da Igreja Católica à contracepção e à prática sexual livre e autônoma não é condizente com a realidade dos fiéis. Para elas, há uma defasagem entre o que a Igreja prega e o que os católicos vivem, devendo-se, portanto, alinhar os dois discursos no sentido de um movimento pelas liberdades sexuais e reprodutivas individuais. Mas não é só: o clero católico esteve de lobby presente desde a fundação do Estado brasileiro independente, tendo legislado indiretamente sobre a vida da população - religiosa ou não - sob a máscara do Estado laico. Assim, limitou referidos direitos.

Católicas advoga pelo fim de qualquer influência religiosa sobre temáticas de direitos humanos, bem como pretende transformar a cultura de controle dos corpos femininos por instituições e indivíduos que não as próprias mulheres:

Quem possui o poder de controle sobre o corpo feminino: o Estado, as autoridades religiosas, as corporações médicas, o chefe da família (marido ou pai) ou as próprias interessadas? [...] recusando-se a que o debate seja remetido para a esfera privada (HIRATA et al, 2009).

Para esta corrente laica, o aborto é um direito civil, uma questão de liberdade individual na qual o Estado não deve interferir (Idem).

Doravante, a questão encontra outro fator de arguição: a complexa e controversa localização da mulher e da religião nos âmbitos público e privado. $\mathrm{Na}$ tradição patriarcal, às mulheres é 
destinada a esfera privada, do lar e da família. Ao se alijarem desta esfera, se expõem a ataques à própria integridade:

o discurso das esferas separadas alimenta e se nutre de um discurso da diferença "natural" entre os sexos, que distribui os papéis sociais segundo a filiação sexual. [...] O homem público obtém consideração; a mulher pública é objeto de escárnio (HIRATA et al, 2009, p. 210).

Interessantemente, Católicas confere à religião semelhante esfera, tencionando promover uma inversão, na qual a religião esteja para o privado, a voz feminina para o público e as suas decisões individuais, para o privado"[...] religião deve ser matéria de ética privada, e políticas públicas de saúde não devem ser fundamentadas em místicas religiosas sobre o bem viver" (DINIZ, 2013).

Se advogam pela laicidade estatal e por exigências não tradicionalmente identificadas com a comunidade católica, por quê "Católicas" e não "Mulheres pelo direito de decidir"? Pela necessidade de divergir do que é considerado conservador na doutrina religiosa e para marcar seus objetivos de:

(1) [...] igualdade nas relações de gênero na sociedade, na Igreja Católica e em outras religiões. Adotamos a corrente de pensamento ético-religioso feminista pelo direito de decidir, que reconhece a autoridade moral e capacidade das mulheres de tomar decisões livremente em todos os campos de suas vidas ${ }^{3}$;

(2) "Conscientizar a sociedade de que a experiência humana da sexualidade e da reprodução de todos e todas deve ser reconhecida, respeitada e vivida de forma autônoma e livre"; (3) "Promover o diálogo inter-religioso e uma cultura de respeito à livre expressão religiosa"; (4) "[...] articular as ideias do feminismo com o cristianismo, buscando argumentação teológica consistente [....]"; (5)

3Todas as citações enumeradas disponíveis em: <http://catolicas.org.br/institucional$2 /$ nosso-trabalho/>, referenciado ao final 
A difusão de outras formas de compreender a religião, dialogando com outras igrejas de modo a se somar ao movimento feminista.

Dessa forma, portanto, a religião poderia estar presente e obter validade na esfera pública cultural da sociedade plural brasileira, sem ferir seus princípios democráticos liberais. Isto é: ao marcar sua participação política enquanto movimento social ${ }^{4}$ - através de advocacy e em audiências públicas 5 - e conter proposições teológicas distintas em sua própria nomenclatura, o grupo já se destaca enquanto grupo religioso atuante na esfera pública e, sobretudo, em consonância com princípios democráticos seculares.

Habermas problematiza questões levantadas no âmbito da bioética, como o aborto, nas quais

as maiorias seculares não deveriam tomar nenhuma resolução, pelas quais os cidadãos religiosos se sentiriam feridos em suas convicções de fé, até que estes sejam suficientemente ouvidos em sua objeção; as maiorias seculares "devem considerar esta objeção como um tipo de veto protelador, para avaliar o que podem aprender com ele" (KNAPP, 2011, p. 186).

Para o autor, a ação descrita é imprescindível para o exercício da tolerância religiosa, por extenuante que seja para grupos progressistas a repetição de argumentos vindos de grupos de grupos religiosos conservadores, hoje mais contundentes pela incorporação da modernidade (da ciência) em seu discurso. Sobre este aspecto do pensamento habermasiano, Bacha e Silva nos lembra que

para uma convivência pacífica de diferentes comunidades religiosas, deve haver uma renúncia a

\footnotetext{
4 Autointitula-se "movimento social" em: http://catolicas.org.br/institucional2/historico/.

${ }^{5}$ Católicas esteve presente na audiência pública sobre a ADPF 442 no Supremo Tribunal Federal, representada oficialmente pela socióloga Maria José Rosado (http://catolicas.org.br/novidades/noticias/confira-discurso-de-catolicas-naaudiencia-publica-sobre-a-adpf-442-no-stf/) e pelo discurso da antropóloga Débora Diniz (https://medium.com/qg-feminista/o-discurso-de-debora-diniz-peladescriminalizacao-do-aborto-884169d96982).
} 
meios de coação política para imposição de fé, bem como a eliminação de qualquer tipo de coação moral contra os próprios membros das confissões religiosas. [...] deve haver um respeito pelo ethos do outro. Mesmo que a religião seja uma forma de vida em sua totalidade, em sociedades pluralistas e democráticas, a religião deve renunciar a tal pretensão, já que a vida da comunidade política é mais ampla do que a vida da comunidade religiosa (2017, p. 81).

Elucida-se, aqui, a compatibilidade lograda por Católicas no exercício de sua cidadania laica e sua afirmação enquanto segmento de fiéis preocupadas tanto em afirmar seu credo quanto garantir direitos para crentes e não crentes de outras religiões.

\section{Conclusões preliminares}

Diante do exposto, podemos voltar, por exemplo, a José Casanova enquanto defensor da desprivatização da religião, situação complementar à da dessecularização enxergada por Berger: no caso brevemente exposto neste trabalho, a Igreja Católica continua se colocando como religião pública, participando da disputa igualmente pública em sentido exógeno à sua comunidade, ainda tratando de temas que afetam uma população plural. Tal atuação não necessariamente deve ser interpretada como anti-moderna, antisecular ou anti-democrática, uma vez que os argumentos provenientes de religiosos têm incorporado eficientemente conteúdo considerado "atual", simplesmente pela citação de trabalhos das Ciências Biológicas. Pois, se a posição católica tradicional pode aludir a profissionais que considerem a origem da vida como o momento da concepção, Católicas pode aludir à defesa da legalização do aborto como questão de saúde pública e proteção da mulher.

Ainda que com menos expressão hoje devido ao avanço do neopentecostalismo, pode-se afirmar, dada sua história de função aglutinadora e consertadora da sociedade brasileira, que o catolicismo 
ainda é uma religião pública. E mais: a nível social, apesar de Católicas pelo Direito de Decidir encontrar-se numa área difusa entre movimento social e religioso ${ }^{6}$, sua presença e autoafirmação já se valem como tentativa de reforma da doutrina referente à própria confissão e de fazer frente ao conservadorismo cristão de forma geral.

Não obstante, Casanova nos é essencial nesta conclusão, para não retornarmos à introdução deste trabalho, e exercermos atividade crítica sobre nossos próprios preconceitos despertados pela simples denominação religiosa de grupos que interferem na opinião pública e, em medidas diferentes, sobre a jurisdição brasileira. Pois bem, em primeiro lugar, a disputa entre grupos religiosos e advogadas dos direitos sexuais e reprodutivos justifica-se: (a) pela substituição do comunismo pelo feminismo como "'o espectro' rondando todas as tradições religiosas" (CASANOVA, 2009, p.4, tradução nossa); (b) pela correlação obrigatória entre os discursos feminista e laico, da mesma maneira que o comunismo e o ateísmo no século XIX (idem), de tal maneira que - como observado em Católicas - se enxergue no conservadorismo religioso o principal obstáculo para o avanço dos direitos das mulheres, defendendo, então, a secularização do Estado, da política e da moralidade (p. 5).

Ademais, o autor diferencia três tipos de problemáticas na política religiosa do gênero, podendo-se inserir as Católicas no terceiro: "[...] a questão sobre o quê mulheres como sujeitos religiosos fazem e pensam, essa é a questão da agência histórica das mulheres hoje na reprodução e transformação de suas tradições religiosas" (p. 6). Ou seja, será a agência das mulheres e o papel desempenhado por elas na reprodução ou não de suas próprias tradições que decidirá o destino das tradições.

Destarte, embora a intenção da organização seja de separação e de proteção mútua entre religião e Estado, a estritez dela não é

6Pois pretende uma teologia alternativa (feminista) e a reorganização da instituição católica de maneira a promover a igualdade entre mulheres e homens. 
suficiente para o grupo alcançar seus objetivos. No caso apresentado, dado em parte à pretensão de revisionismo, a religião funciona como força catalisadora de mudanças sociais e políticas, pois, "Na condição de fiéis, as mulheres podem se sujeitar ao poder disciplinar das religiões, mas, por sua ação, podem igualmente contribuir para sua mudança" (ROSADO, 2009, p. 214). Católicas pelo Direito de Decidir disputa com a Igreja a atualização da moralidade pública, ainda que singelamente, abrindo em si a possibilidade de empenho como um movimento de base para reformas. No recente caso do aborto realizado numa criança de 10 anos vítima de estupro, por exemplo, ainda que o direito já seja previsto em lei, setores católicos tradicionais foram veemente e violentamente contrários ao procedimento ${ }^{7}$. As Católicas, por sua vez, juntaram-se à Frente Evangélica pela Legalização do Aborto $^{8}$ para defender o direito já previsto e opuseram posições religiosas reacionárias junto a setores seculares da sociedade.

Finalmente, temos a pretensão de dar continuidade à discussão da temática a fim de se configurar como artigo de publicação em revista científica. Visamos incluir outras denominações cristãs e os embates internos a elas entre fiéis inclinados ao secularismo e autoridades religiosas conservadoras, bem como as perspectivas feministas sobre a legalização do aborto.

\section{Referências}

BACHA E SILVA, Diego. Laicidade e Estado Democrático de Direito: Sobre a relação entre direito, religião e o agir prático. Revista da Faculdade de Direito-RFD-UERJ, Rio de Janeiro, n. 31, p. 69-85, jun. 2017.

7Regional Sul 1 da CNBB emite nota sobre estupro de menina e aborto no ES, disponível em: https://cnbbsul1.org.br/regional-sul-1-da-cnbb-emite-nota-sobreestupro-de-menina-e-aborto-no-es/. Acesso em: 30 ago. 2020.

${ }^{8}$ Cristãs pela legalização do aborto: $\mathrm{O}$ que elas têm a dizer sobre o caso da menina estuprada no Espírito Santo?, disponível em: https://maxima.uol.com.br/noticias/comportamento/cristas-pela-legalizacao-doaborto-o-que-elas-tem-dizer-sobre-o-caso-da-menina-estuprada-no-espiritosanto.phtml. Acesso em: 30 ago. 2020. 
BERGER, Peter. A dessecularização do mundo: uma visão global. Religião e Sociedade, Rio de Janeiro, v. 21, n. 1, p. 9-24, 2000.

CASANOVA, José. Public Religions Revisited. International Conference Religion revisited: women's rights and the political instrumentalisation of religion. Heinrich-Böll-Foundation \& United Nations Research Institute for Social Development (UNRISD), Berlin, 5-6 June 2009.

CATÓLICAS pelo Direito de Decidir. Histórico. Disponível em: http://catolicas.org.br/institucional-2/historico/. Acesso em: 30 ago. 2020.

DINIZ, Débora. Estado laico, objeção de consciência e políticas de saúde. Perspectivas, Cad. Saúde Pública, Rio de Janeiro, v. 29, n. 9, p. 1074-1076, set. 2013.

HIRATA, Helena; Laborie, Françoise; Le Doaré, Hélène; Senotier, Danièle (Org.). Dicionário crítico do feminismo. São Paulo: Ed. UNESP, 2009. Verbetes: Aborto e contracepção; Público/privado; Religiões.

KNAPP, Marcus. Fé e saber em Jürgen Habermas - A religião numa sociedade "pós-secular". Interações - Cultura e Comunidade, Uberlândia, v. 6, n. 10, p. 179-192, jul./ dez. 2011.

MARIANO, Ricardo. Laicidade à brasileira: católicos, pentecostais e laicos em disputa na esfera pública. Civitas: Revista de Ciências Sociais, v. 11, p. 238-258, 2011.

Nosso Trabalho. Disponível em: http://catolicas.org.br/institucional2/nosso-trabalho/. Acesso em 30 ago. 2020.

ROSADO, Maria José. Verbete: Religiões. In: HIRATA et all. Dicionário crítico do feminismo. São Paulo, Ed. UNESP, 2009. 